\title{
Pediatric Spinal Cord Injury without Neuroimaging Abnormality (SCIWNA): A Clinico-Radiological Conundrum
}

\author{
Kamer Singh Rana, MD (Paed) ${ }^{1 *}$, Jyotindra Narayan Goswami, MD (Paed), DNB (Paed), DM (Paed \\ Neurology), MNAMS² and Dinesh Sareen, MD (Internal Medicine), DM (Neurology) ${ }^{1}$ \\ ${ }^{1}$ Department of Neurology \& Pediatric Neurology, Venkateshwar Hospital, New Delhi, India \\ ${ }^{2}$ Department of Pediatrics, Army Hospital (Research \& Referral), New Delhi, India

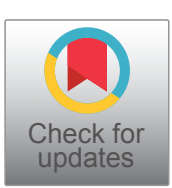

\begin{abstract}
'Spinal Cord Injury Without Neuroimaging Abnormality' (SCIWNA) is a clinico-radiological entity characterized by clinical markers of traumatic myelopathy without neuroimaging evidence of spinal instability or fracture, which is being increasingly recognized among children with the growing application of Magnetic Resonance Imaging (MRI). A child with SCIWNA is being reported to sensitize clinicians about this entity and to highlight the key aspects that aid in its early diagnosis and effective management.
\end{abstract}

Keywords

SCIWORA, Magnetic resonance imaging, SCIWNA

Abbreviations

SCIWORA: Spinal Cord Injury without Radiographic Abnormality; MRI: Magnetic Resonance Imaging; SCIWNA: Spinal Cord Injury without Neuroimaging Abnormality

\section{Introduction}

'Spinal Cord Injury without Radiographic Abnormality' (SCIWORA) is a clinico-radiological entity characterized by clinical markers of traumatic myelopathy without radiographic evidence of spinal fracture/dislocation or ligament injury [1,2]. When spinal Magnetic Resonance Imaging (MRI) is normal in such children, these cases are classified as 'Spinal Cord Injury without Neuroimaging Abnormality' (SCIWNA). Diagnosis and management of pediatric SCIWNA poses unique challenges. We report a child with SCIWNA secondary to low back trauma to sensitize clinicians about this entity and to highlight the importance of early suspicion for its timely diagnosis and effective management.

\section{Case}

Two-year-old developmentally normal male toddler was brought with complaints of irritability and inability to walk for one day. Child was apparently kicked by an adolescent on his low back while playing, following two hours of which he developed inability to walk. Child was taken to a local physician who administered intramuscular and oral analgesics without any effect. Child developed constipation but did not have any urinary symptoms. There was no history suggestive of facial or upper limbs weakness, seizures, altered sensorium, vomiting, feeding or breathing difficulty.

On examination, child was irritable but consolable and oriented to parents. His vital parameters were normal. Examination of cranial nerves and upper limbs was unremarkable. His lower limbs were maintained in an attitude of external rotation with absent spontaneous movements. Muscle power across bilateral hip, knee and ankle joints was zero by Medical Research Council (MRC) grading. Deep

*Corresponding author: Kamer Singh Rana, MD (Paed), Senior Consultant and Head, Department of Neurology \& Pediatric Neurology, Venkateshwar Hospital, Sector 18A, Dwarka, New Delhi, 110075, India, Tel: 910056737

Accepted: September 18, 2021

Published online: September 20, 2021

Citation: Rana KS, Goswami JN, Sareen D (2021) Pediatric Spinal Cord Injury without Neuroimaging Abnormality (SCIWNA): A Clinico-Radiological Conundrum. J Pediatr Neurol Neurosci 5(2):172-174 
tendon reflexes in lower limbs were absent and plantars were mute. Child responded to pain and deep pressure. Examination of abdomen, cardiovascular and respiratory systems was unremarkable. There was no local swelling or deformity over spine.

Radiographs of child's hip joints, lower spine and lower limbs and Magnetic Resonance Imaging (MRI) of the spine was normal. He was diagnosed as a case of SCIWNA and managed with injection methyl prednisolone $30 \mathrm{mg} / \mathrm{kg}$ over one hour followed by $5 \mathrm{mg} / \mathrm{kg} /$ hour for the next 23 hours. Within 24 hours, his lower limb power improved to Grade 3/5 both proximally and distally. His constipation resolved over 48 hours.

Child was discharged on oral prednisolone. At seventh-day follow-up, he could walk with support and had no urinary/ bowel complaints. His deep tendon reflexes continued to be absent. Steroids were tapered over 6 weeks. As there was no bony/spinal cord injury on neuroimaging, child was advised physiotherapy.

\section{Discussion}

SCIWNA has varied presentations ranging from mild, transient illness to severe, irreversible spinal cord damage [1]. The high incidence of SCIWNA amongst children to the range of $30-40 \%$ makes a strong case in point for considering any child with possible injury to the spine to have SCIWNA $[2,3]$. Index case is an example of the same. Until the age of 8-years, neurological injuries tend to be severe. Over half of the injuries in young children occur in the thoracic spine; almost all of these thoracic injuries are severe. Adolescents sustain less severe, typically incomplete injuries. A delay in the onset of neurological deficits or a delayed neurological deterioration had been reported. Brief transient motor or sensory symptoms are often associated with the initial injury. An asymptomatic period usually intervenes. The delays in deficits can range from hours to 4 days after injury.

The preponderance of SCIWNA in children has been postulated to be secondary to certain factors such as their disproportionately large head size and unique vertebral characteristics such as elastic ligamentous structures, immature bony structures, horizontally oriented facet joints [2]. Hyperextension injuries, direct impact and peculiarities of biomechanical forces on the pediatric vertebral column may result in SCIWNA as a result of temporary compression of vertebral artery $[1,4]$. There was antecedent history of trauma in index child but the exact biomechanical event was not evident as in most cases. Injuries may be due to direct spinal cord injury such as compression, traction, concussion and indirect injuries such as vascular compromise and hypotension, compression of spinal cord and subclinical fractures.

Differential neurological deficits with upper limbs being more severely affected than lower limbs is common occurence in SCIWNA $[5,6]$. There may be delayed expression of symptoms up to 48 hours post-injury due to recurring microinsults owing to the unstable vertebrae [1]. Hence SCIWNA needs to be suspected despite absence of obvious history if clinical pointers are present. The key differential diagnoses that need to be considered include compressive myelopathy and demyelinating disorders such as transverse myelitis, acute disseminated encephalomyelitis and Neuromyelitis Optica Spectrum Disorder (NMOSD).

Conventional radiography of spine may detect up to $75 \%$ of vertebral fractures with $85 \%$ sensitivity whereas Computed Tomography (CT) is more sensitive for detecting bony injuries [1]. MRI is the current gold standard for investigation as cases, which would have been labeled as SCIWORA based on radiography and CT alone may have spinal cord hyperintensities in MRI Diffusion Weighted Imaging (DWI) [7]. Those with normal MRI are classified as spinal cord injury without neuroimaging abnormality (SCIWNA) [7]. Spin-echo T1 (T1 SE), short tau inversion recovery (STIR) weighted MRI , gradient-echo $\mathrm{T}^{*}$ (T2-weighted $\mathrm{GRE}^{*}$ ) are other sequences preferred in spinal cord imaging for post-trauma workup [1].

Spinal stabilization by application of brace or cervical collar till resolution of neurological symptoms forms the core of SCIWNA management $[1,8]$. High dose steroids (intravenous methyl prednisolone bolus at a dose of $30 \mathrm{mg} / \mathrm{kg}$ within 8 hrs of injury, followed by infusion at $5.4 \mathrm{mg} / \mathrm{Kg} / \mathrm{hr}$ for the next $23 \mathrm{hrs}$ ) is known to benefit these patients while rarely, they may require surgical interventions such as vertebral fusion in case of unstable vertebrae [8]. There is evidence of high-dose methyl prednisolone therapy as the sole therapy having efficacy if administered within eight hours of injury and possibility of additional benefit when maintenance is given for 48 hours instead of 24 hours [9]. Index child showed excellent response to delayed initiation of steroid therapy.

Long term prognosis of SCIWNA depends on the presenting neurological deficits and degree of spinal cord injury $[1,3,7]$. Among individuals with SCIWNA,children generally have better long term outcomes than adults [3].

\section{Conclusion}

To conclude, the case is an attempt to sensitize readers about the entities of pediatric SCIWORA and SCIWNA. The role of early clinical suspicion, imaging, management including the possible benefit of corticosteroid therapy even when exhibited after 24 hours of injury and the necessity of follow-up in SCIWNA is underscored by the report.

\section{Source of Support}

Nil.

\section{Conflicting Interest}

Nil.

\section{Acknowledgement}

Nil. 
Citation: Rana KS, Goswami JN, Sareen D (2021) Pediatric Spinal Cord Injury without Neuroimaging Abnormality (SCIWNA): A ClinicoRadiological Conundrum. J Pediatr Neurol Neurosci 5(2):172-174

\section{Contribution Details (to be ticked marked as applicable):}

\begin{tabular}{|l|c|c|l|}
\hline & K S Rana & J N Goswami & D Sareen \\
\hline Concepts & $\square$ & $\square$ & $\nabla$ \\
\hline Design & $\square$ & $\square$ & $\square$ \\
\hline $\begin{array}{l}\text { Definition of intellectual } \\
\text { content }\end{array}$ & $\square$ & $\square$ & $\square$ \\
\hline Literature search & $\square$ & $\square$ & $\square$ \\
\hline Clinical studies & $\square$ & $\square$ & $\square$ \\
\hline Experimental studies & & & \\
\hline Data acquisition & $\square$ & $\square$ & $\square$ \\
\hline Data analysis & & $\square$ & $\square$ \\
\hline Statistical analysis & & & \\
\hline Manuscript preparation & $\square$ & $\square$ & $\square$ \\
\hline Manuscript editing & $\square$ & $\square$ & $\square$ \\
\hline Manuscript review & $\square$ & $\square$ & $\square$ \\
\hline Guarantor & $\square$ & & \\
\hline
\end{tabular}

1. Szwedowski D, Walecki J (2014) Spinal Cord Injury without Radiographic Abnormality (SCIWORA) - Clinical and Radiological Aspects. Polish J Radiol 79: 461-464.

2. Wyndaele JJ (2016) SCIWORA. Spinal Cord 54: 755-755.

3. Launay F, Leet Al, Sponseller PD (2005) Pediatric spinal cord injury without radiographic abnormality: A meta-analysis. Clin Orthop Relat Res 433: 166-170.

4. Parent S, Mac-Thiong J-M, Roy-Beaudry M, et al. (2011) Spinal cord injury in the pediatric population: A systematic review of the literature. J Neurotrauma 28: 1515-1524.

5. Baumann F, Ernstberger T, Neumann C, et al. (2015) Pediatric Cervical Spine Injuries. J Spinal Disord Tech 28: 377-384.

6. El Masri WS, Kumar N (2011) Traumatic spinal cord injuries. Lancet 377: 972-974.

7. Yucesoy K, Yuksel KZ (2008) SCIWORA in MRI era. Clin Neurol Neurosurg 110: 429-433.

8. Atesok K, Tanaka N, O'Brien A, et al. (2018) Posttraumatic Spinal Cord Injury without Radiographic Abnormality. Adv Orthop 2018: 1-10.

9. Bracken MB (2012) Steroids for acute spinal cord injury. Cochrane Database Syst Rev 1: CD001046.

DOI: $10.36959 / 595 / 432$

Copyright: (c) 2021 Rana KS, et al. This is an open-access article distributed under the terms of the Creative Commons Attribution License, which permits unrestricted use, distribution, and reproduction in any medium, provided the original author and source are credited. 